\title{
Conselhos de Saúde: controle social e moralidade
}

\section{Health Councils: social control and morality}

\section{Rodrigo Batagello}

Doutorando do Programa de Pós-graduação em Bioética e da Cátedra UNESCO de Bioética da Faculdade de Ciências da Saúde. Universidade de Brasília.

Endereço: Cátedra Unesco de Bioética, Faculdade de Ciências da Saúde, Campus Universitário Darcy Ribeiro, Caixa Postal 04451, CEP 70910-900, Asa Norte, Brasília, DF, Brasil.

E-mail: rodrigo-batagelloळuol.com.br

\section{Luciana Benevides}

Doutoranda do Programa de Pós-graduação em Bioética e da Cátedra UNESCO de Bioética da Faculdade de Ciências da Saúde. Universidade de Brasília.

Endereço: Cátedra Unesco de Bioética, Faculdade de Ciências da Saúde, Campus Universitário Darcy Ribeiro, Caixa Postal 04451, CEP 70910-900, Asa Norte, Brasília, DF, Brasil.

E-mail: lucianabenevidesळgmail.com

\section{Jorge Alberto Cordón Portillo}

Doutor em Ciências da Saúde. Professor Adjunto da Faculdade de Ciências da Saúde e do Programa de Pós-graduação em Bioética da Universidade de Brasília.

Endereço: Cátedra Unesco de Bioética, Faculdade de Ciências da Saúde, Campus Universitário Darcy Ribeiro, Caixa Postal 04451, CEP 70910-900, Asa Norte, Brasília, DF, Brasil.

E-mail: colectiva_jacpळyahoo.com.br

\section{Resumo}

A estrutura formada pelos conselhos de saúde representa um exemplo de como a democracia participativa é fundamental na legitimação das decisões sobre a gestão da saúde pública. A atuação desses conselhos avança para além da deliberação técnica e jurídica, alcançando a dimensão dos conflitos morais, onde elas são reorientadas à luz de uma ordem de deliberações que pode ser denominada moral. O estudo da Teoria das Ordens de Comte-Sponville pode auxiliar na compreensão da ordem moral no papel desempenhado pelos conselhos de saúde, bem como permite avaliar os desafios que se colocam para a manutenção e para a eficácia dessa estrutura na concretização das políticas de saúde no Brasil. 0 autor faz referência às ordens tecnocientífica e jurídico-política e destaca a necessidade de limitar estas ordens por meio da moralidade. A partir desse modelo teórico e da contribuição de autores nacionais, o presente artigo tenta compreender a estrutura adotada pelos conselhos de saúde e a ordem específica de manifestação do controle social.

Palavras-chave: Conselhos de Saúde; Políticas de Controle Social; Participação Comunitária; Bioética. 


\section{Abstract}

The structure formed by the Health Councils represents an example of the importance of participatory democracy for the legitimation of the decisions on public health management. The existence of social control mechanisms of Brazilian public policies is also indispensable to the analysis of the subject matter in light of bioethics. Accordingly, the study of Comte-Sponville's ideas can aid the understanding of the role played by the Health Councils. The author refers to the techno-scientific and juridical-political orders, and he highlights the need to limit those orders through morality. Based on this theoretical model, the article attempts to comprehend the structure adopted by the Health Councils and the specific order of manifestation of social control. Finally, it emphasizes the importance of the consolidation of participatory forums and their capacity for aiding the democratization of the Brazilian institutions, as well as the need of increasing the social movements' participation, indicating that mobilization cannot be limited to the formal spaces of social control. Keywords: Health Councils; Social Control Policies; Community Participation; Bioethics.

\section{Introdução}

A exclusão social, a pobreza e as diferentes formas de discriminação são condições que as sociedades contemporâneas ainda vivenciam e perpetuam. Apesar dos avanços tecnológicos, os problemas sociais e econômicos permanecem ainda como os grandes desafios a serem superados, tornando-se temas sempre presentes nas discussões sobre a saúde pública e a bioética (Garrafa, 2005a).

A discussão sobre a ética na saúde pública, uma das prioridades temáticas da bioética na América Latina, atenta para os conflitos morais produzidos na condução das políticas públicas, uma vez que podem limitar ou restringir as liberdades individuais em nome do interesse público. Esses conflitos tornam-se ainda mais profundos quando o discurso do interesse público encontra pouco ou nenhum respaldo na realidade vivida cotidianamente pelos cidadãos, resumindo-se a uma expressão estritamente formal e com pouco alcance prático (Spink, 2007).

A justa distribuição de recursos e a responsabilidade do estado na implementação de políticas públicas, sem incorrer na discriminação de grupos já submetidos a situações de maior vulnerabilidade, também deve ser considerada. Nesse sentido, enfatiza-se a importância da adoção de políticas e medidas práticas (Garrafa e Porto, 2002), fundamentadas na equidade e na responsabilidade social, para minimizar situações de exclusão e desigualdade (Garrafa, 2005a), observando-se a diferença entre pessoas ou grupos humanos, dando-lhes a oportunidade de se manifestar e de participar das decisões, o que se traduz no empoderamento dos sujeitos e na sua inserção social (Cruz e Trindade, 2006).

No caso brasileiro, destaca-se a especial importância da discussão sobre os mecanismos de controle social das políticas públicas. Nesse sentido, o Brasil oferece lições importantes ao criar mecanismos institucionais inovadores para o envolvimento popular e responsabilidade na gestão do Sistema Único de Saúde (SUS), moldando a participação como um direito (Cornwall e Shankland, 2008).

As estruturas formadas pelos conselhos de saúde representam um exemplo de como a democracia participativa é fundamental na legitimação das decisões sobre a gestão da saúde pública. Pela com- 
posição plural, os conselhos constituem espaços de controle social, sendo esse conceito compreendido como a capacidade da sociedade civil de promover um enfrentamento moral que permite uma ponderação entre as decisões tecnicamente orientadas, as juridicamente balizadas e as socialmente desejadas.

Essa característica peculiar dos conselhos de saúde é que instigou a discussão que se apresenta a seguir sobre a dimensão moral da atividade dos conselhos de saúde. No presente artigo, espera-se contribuir para a compreensão do papel dos conselhos de saúde, a partir da reflexão sobre as ideias do filósofo francês André Comte-Sponville.

A proposta é apresentar uma interpretação original para o desempenho do chamado controle social pelos conselhos de saúde, baseada na aplicação de uma estrutura conceitual elaborada por ComteSponville para a interpretação da moralidade do sistema de produção capitalista.

\section{Controle Social: a reinvenção de um conceito}

O Sistema Único de Saúde foi concebido no interior de um contexto político onde a descentralização e a participação difusa nas esferas de decisão eram valores primordiais. A ressaca provocada por mais de duas décadas de governo totalitário imprimiu uma dinâmica que pretendeu, em todos os espaços possíveis, garantir o máximo de abertura para a participação dos diversos componentes da sociedade civil na estrutura que a nova constituição edificava.

A ideia de conselhos plurais, articulados nas três esferas de governo e com um alcance capilar em todo o território nacional, parecia o melhor modelo para uma organização da estrutura de gestão da saúde. Essa configuração garante, a um só tempo, que os usuários do sistema público de saúde possam ter representatividade política no processo de tomada de decisões e, ainda, estabelece uma estrutura com a capacidade de introduzir a compreensão das necessidades da população local e orientar as ações de saúde em função das diferentes realidades que compõem o cenário da saúde no país.

A inovação dessa proposta se apoia, portanto, no fato de os conselhos assumirem um importante pa- pel epidemiológico e, concomitantemente, abrirem espaço para o protagonismo dos usuários (Brasil, 2006, p. 18).

Entre as várias consequências da adoção desse modelo de gestão, a sua concepção passou a refletir uma nova compreensão do processo saúde-doença. Tratou-se de questionar a centralidade ou a predominância do marco técnico (médico) - que tradicionalmente era utilizado como referencial para as decisões nas políticas de saúde pública - e de criar instrumentos para abarcar os anseios da sociedade civil organizada.

Conferindo uma leitura francamente progressista a um conceito com um histórico marcadamente conservador, no contexto do Sistema Único de Saúde (SUS) passou-se a identificar a possibilidade de participação da sociedade civil nos processos decisórios da gestão da saúde por meio da expressão controle social.

É interessante destacar que esse conceito, no pensamento filosófico e sociológico modernos, ora foi utilizado para designar uma consequência da democracia participativa, ora uma condição de sua própria possibilidade.

A interpretação de que o controle social exerce a função de um artifício regulador dos conflitos ideológicos no âmbito da gestão da saúde pública e que tem a função de contrabalançar o uso que as forças políticas conservadoras faziam do aparato estatal é inaugurada pelo SUS e seus documentos (Brasil, 2006, p. 21), conforme segue:

O controle social, assim, além de publicizar, democratizar e criticar a relação do Estado com os interesses dominantes, é, paradoxalmente, uma instituição em movimento, que promove a presença dos movimentos sociais na agenda governamental. [...] 0 controle social possibilita que se olhe o processo histórico da correlação de forças e a saúde como questão disputada nas lutas sociais, da qual querem se apropriar os gestores, os burocratas, o capital financeiro, os planos de saúde, o capital de investimentos nos serviços de saúde.

Tal expressão era utilizada de forma recorrente por diferentes autores para caracterizar um poder 
estatal capaz de realizar a manutenção da ordem social ou de construir ordens e identidades sociais específicas, fosse ele um poder centralizado ou difuso. 0 primeiro sentido, controle social como poder central responsável pela manutenção da ordem vigente, apareceu nas teorias clássicas da Sociologia, principalmente em Durkheim e Comte (Alvarez, 2004).

Guardadas as devidas limitações e diferenças específicas, a expressão designava os aparatos (simbólicos ou materiais) de manutenção da ordem social, com o objetivo de garantir e, em determinados casos, restabelecer a integração social (Alvarez, 2004).

No período pós-guerra, principalmente a partir da década de 1960, o tema passa a ter uma conotação estritamente negativa, uma vez que aponta para as estratégias estatais organizadas de correção daqueles comportamentos tidos como desviantes. A obra de Foucault traz uma importante contribuição para a compreensão dos mecanismos de dominação utilizados na manipulação, formatação e homogeneização do corpo social, reunidos pelo autor sob a expressão controle social e biopolítica (Silva, 2008).

Segundo Silva (2008), a introdução do conceito de controle social no vocabulário acadêmico-militante e sua legitimação normativa na Constituição brasileira de 1988 foram influenciadas pela perspectiva gramsciana de análise do Estado e da sociedade civil, que levava à compreensão dessa própria sociedade civil como sujeito responsável pelo controle exercido sobre o Estado.

Contudo, ele destaca que na releitura do conceito promovida no contexto brasileiro, o controle social passou a ser largamente considerado como a possibilidade de ampliação da cidadania, principalmente nos aspectos relacionados à construção da democracia (Silva, 2008).

Foi justamente o desenvolvimento dessa compreensão e a construção desse novo significado para essa expressão que passaram a caracterizar o trabalho dos conselhos de saúde e, por conseguinte, despertar o interesse pela discussão da atuação e das decisões oriundas desses conselhos, identificados agora como espaços legítimos para o exercício do controle social.

\section{A Ordem Moral como Dimensão Específica de Atuação do Controle Social}

A defesa conjunta da democracia participativa e do controle social efetivo, que sustenta ideologicamente o SUS, guarda um duplo registro: é uma aspiração política que se materializa em um determinado modelo de organização e gestão da saúde; e é um reflexo da reforma sanitária brasileira, que pretendeu romper com a centralidade da atenção médica, de origem flexineriana, e instituir um modelo que "politiza tanto o diagnóstico como as ações de saúde" (Brasil, 2006, p. 18).

Esse duplo registro permite uma leitura sobre a hierarquização das decisões segundo os critérios que as sustentam. Para realizar essa leitura, foi utilizado o modelo teórico elaborado por Comte-Sponville, em seu texto $O$ capitalismo é moral?. Neste livro, o autor francês discute as diferentes ordens que orientam as decisões e as ações humanas, esclarece o limite de cada uma delas e explora as relações que entre elas se estabelecem.

O estudo das ideias de Comte-Sponville pode auxiliar na compreensão do papel, ao menos teórico, desempenhado pelos conselhos de saúde, considerados na sua dimensão de espaços de controle social. Para tanto, é necessário expor alguns conceitos básicos oferecidos pelo autor.

De acordo com ele, as decisões e as ações humanas estão organizadas em âmbitos específicos, cada qual com um referencial conceitual próprio a orientar as deliberações dos agentes e dotados de um alcance limitado de legitimação. De modo geral, todas as ações humanas estariam necessariamente submetidas às esferas do como fazer e do dever fazer.

A partir desses dois âmbitos, Comte-Sponville posiciona em diferentes ordens as áreas do conhecimento humano, principalmente aquelas relacionadas com a vida prática, ou seja, que afetam diretamente o plano das ações individuais e coletivas.

Cada uma dessas ordens reúne o referencial teórico e conceitual necessários para a resolução dos problemas que lhes são próprios, contudo, elas estão 
dispostas em uma escala valorativa que as organiza de forma hierárquica, o que estabelece, por sua vez, um limite para o alcance de sua aplicação.

A função dessa escala valorativa proposta por Comte-Sponville é estabelecer a relação entre o campo de pertinência e a capacidade de legitimação de um dado conhecimento quando se intenciona transformá-lo em referência para as ações. Não se trata, portanto, de contrapor epistemologicamente as diferentes áreas científicas, mas de questionar a amplitude da legitimidade que ela pode oferecer quando o assunto é a responsabilidade moral.

Assim, o próprio desenvolvimento econômico e social deve ser compreendido como uma associação entre a viabilidade técnico-científica, a sua regulação jurídica e sua legitimidade social, essa última garantida pela moralidade.

Segundo Comte-Sponville, uma primeira ordem possível é a tecnocientífica. Nela são elaboradas as respostas para os problemas no âmbito do como fazer. Ou seja, nessa primeira ordem é elaborada e debatida a viabilidade científica e técnica das ações e decisões humanas.

Tal ordem é representada pelas ciências contemporâneas, em particular pelas ciências aplicadas, que são as grandes produtoras de tecnologia e que podem oferecer respostas que são da dimensão do tecnicamente possível ou impossível, do cientificamente viável ou inviável.

Nesse sentido, não é uma competência científica responder pela questão do dever fazer. As ciências investigam os fenômenos e elaboram teorias que podem fundamentar novas aplicações tecnológicas, mas não podem decidir, por exemplo, se as pessoas devem ou não adotar uma determinada aplicação ou orientação científica (Comte-Sponville, 2005).

Os chamados avanços científicos não se tornam fatos ou se embrenham no cotidiano das pessoas por uma decisão científica ou por deliberação de um conselho de cientistas. Não cabe a eles essa decisão e esse tipo de deliberação está fora da competência da qual estão imbuídos. Segundo Comte-Sponville (2005, p. 51), tal situação se explica pelo fato de essa ordem

[...] estar estruturada internamente pela oposição entre o possível e o impossível. Tecnicamente, há o que se pode fazer (o possível) e o que não se pode fazer (o impossível). Cientificamente, há o que se pode pensar (o possivelmente verdadeiro) e o que não se pode pensar (o possivelmente falso). Mas essa fronteira interna entre possível e impossível é incapaz de limitar a ordem tecnocientífica mesma.

A explicação para essa incapacidade está no fato de que aquilo que é cientificamente possível no interior do movimento de progresso científico e tecnológico não é necessariamente desejado ou legítimo para a sociedade. Além disso, as fronteiras do campo científico obedecem a uma lógica que pode ser perniciosa e até mesmo perigosa se adotarmos a chamada lei de Gabor: "todo o possível será sempre feito" (Comte-Sponville, 2005, p. 52). Além disso, o cientificamente válido não é, necessariamente, intrinsecamente bom.

O autor utiliza o exemplo da economia para explicar o seu raciocínio. Enquanto ciência, ela está preocupada em revelar as leis do mercado e garantir as possibilidades de lucratividade do capital. Ela pode analisar condições, avaliar quais as opções mais lucrativas e apontar os investimentos mais atrativos. Essas capacidades são fruto da sua competência científica e técnica. Contudo, certas movimentações e determinados procedimentos, mesmo que sejam orientados por um caráter exclusivamente técnico, podem produzir estragos imensos no cerne da sociedade (Comte-Sponville, 2005, p. 52).

E essa mesma estrutura pode servir para as ciências da saúde de maneira geral, principalmente se pensarmos a influência exercida por tecnoburocratas na gestão da saúde. E aqui se apresenta o fundamento legítimo que sustenta teoricamente a existência dos conselhos plurais: uma decisão tecnicamente correta não é, necessariamente, a mais legítima socialmente ou a mais adequada moralmente.

Conceitos como socialmente legítimo ou moralmente adequado são estranhos ao fazer científico e a ciência não reúne as condições para deliberar isoladamente sobre eles.

Por outro lado, não significa dizer que os pressupostos e os conhecimentos científicos não são importantes na tomada de decisão e na organização das ações. A conclusão aqui é que apenas a validade científica não é suficiente para conferir legitimidade 
às decisões e às ações, e que o sentimento de dever ultrapassa os limites daquilo que é exequível do ponto de vista científico.

Como afirma Sánchez Vázquez (2002, p. 103),

[...] as ciências são um conjunto de proposições ou juízos sobre aquilo que as coisas são: enunciam ou indicam aquilo que alguma coisa é. Seus enunciados não têm um caráter normativo, isto é, não indicam o que alguma coisa deve ser.

Deve-se, portanto, limitar essa ordem técnicocientífica do exterior, para que nem tudo que seja possível seja, por isso, feito (Comte-Sponville, 2005). Daqui a necessidade de uma segunda ordem, jurídico-política, que regule e estabeleça os limites legais para a ordem técnico-científica.

São os legisladores, como representantes da vontade de um povo soberano, que devem instituir o limite entre a prática legal e a ilegal, a orientação jurídica do que pode ou não ser feito, sem que os interesses maiores da população sejam colocados em risco. Desse modo, nessa ordem existe a oposição entre o que é autorizado por lei (legal) e o que não é autorizado (o ilegal). A construção desses polos é marcada por um jogo de oposições e forças que, no tocante à representação parlamentar, ocorre entre o governo e a oposição. No interior desse jogo, existirá o grupo majoritário, que poderá estabelecer o que é o legal, quando a matéria não depender do consenso.

O Poder Judiciário também desempenha um importante papel nessa ordem, uma vez que ele é o responsável pela aplicação das leis. No caso brasileiro, essa influência pode inclusive ultrapassar os limites da aplicação, chegando o judiciário a exercer influência direta no entendimento e na regulamentação de determinados assuntos, como ocorreu na discussão sobre o uso de embriões humanos em pesquisas

As recorrentes discussões sobre as tecnologias reprodutivas, particularmente as técnicas de clonagem, também são exemplos desse tipo de conflito entre a primeira e a segunda ordem. Conflito no qual o mérito científico é colocado em perspectiva e analisado segundo os interesses políticos e os costumes que caracterizam a sociedade.

Fundamento da democracia representativa, o embate entre os grupos políticos, que se desenrola na arena parlamentar, tem a função de mimetizar, em escala reduzida, as dinâmicas sociais e garantir que as decisões legislativas sejam, na medida do possível, expressões dos anseios e desejos populares materializados no corpus jurídico.

O exercício legislativo tem a atribuição de legitimar socialmente certas práticas, conferindo-lhes um estatuto de ações legalmente corretas, e também de coibir outras tantas, criminalizando-as e decretando sua ilegalidade.

Porém, uma vez que se dedica à discussão e aplicação formal da lei, a ordem jurídico-política também encontra um limite.

Mesmo diante do argumento de que essa ordem estaria estruturada a partir dos princípios democráticos e de que ela seria representativa da vontade social, Comte-Sponville defende a necessidade de limitá-la. Sua justificativa se desenvolve a partir de dois pontos: uma razão individual e outra coletiva.

Tomando como referência o ponto de vista individual, o autor apela ao leitor que imagine um agente fictício que fosse concebido como um legalista perfeito, ou seja, um agente que tomasse a legislação como única e estrita referência para suas ações e que só agisse em conformidade com ela.

Contudo, aponta o autor, "nenhuma lei veda o egoísmo. Nenhuma lei veda o desprezo. Nenhuma lei veda o ódio. Nenhuma lei veda - vejam só - a maldade" (Comte-Sponville, 2005, p. 54). Ou seja, o autor afirma que nada, nesta segunda ordem, afastaria a possibilidade desse "espectro do canalha legalista" (Comte-Sponville, 2005, p. 54). Tampouco pode haver algo na primeira ordem que possa afastá-lo. Então, também essa segunda ordem deve ser limitada "a fim de que tudo o que é tecnicamente possível e legalmente autorizado nem por isso seja feito" (Comte-Sponville, 2005, p. 54). É importante destacar, por exemplo, que o Estado não pode legislar sobre situações que ele próprio não prevê.

No Brasil é muito comum, por exemplo, a expressão brechas legais, por onde passam manadas de atividades imorais. Isso acontece na medida em que a oposição monolítica entre o legal e o ilegal é formal. E, segundo os adeptos do positivismo jurídico, vale apenas o que está escrito na lei. Tal situação cria zonas nebulosas onde determinadas 
ações, francamente imorais, podem ser perpetradas e justificadas, por exemplo, pelo argumento simplista de que não são ilegais.

A grande questão aqui é o reconhecimento de que a legislação não pode ocupar o lugar da consciência moral dos indivíduos e que as pessoas não podem fazer ou deixar de tomar decisões amparando-se apenas no fato de tal ação ser ou deixar de ser legal. A ação moralmente responsável é justamente aquela norteada pela consciência moral das pessoas e independe da formalidade jurídica e da estrutura coercitiva do Estado.

Além disso, existe uma segunda razão para que a ordem jurídica seja limitada: uma razão coletiva. Segundo Comte-Sponville, por soberania popular devemos compreender a capacidade do povo de alterar a própria Constituição Federal. Isso implica dizer que não há lei fundamental, ou seja, não existe lei que possa se impor ao povo soberano, não existe lei que a assembleia popular não possa dissolver, embora a população não possa violá-las enquanto elas vigorarem. Resume o autor: "não há limites democráticos contra a democracia" (Comte-Sponville, 2005, p. 55).

O que se coloca, portanto, é a necessidade de limitarmos novamente essa ordem jurídica do exterior por meio da moralidade. Sobre esse ponto, assim se expressa Comte-Sponville (2005, p. 59):

Se não podemos, individualmente, sermos canalhas legalistas, e se o povo, coletivamente, não pode instituir todas as leis que bem entenda, não é por razões jurídicas ou políticas; é por razões morais [...] É que estamos não só submetidos a certo número de impedimentos técnicos, científicos, econômicos na ordem 1, não apenas a certo número de impedimentos jurídicos e políticos na ordem 2, mas também a certo número de exigências propriamente morais.

Segundo bem observa o autor, a política excede o direito. Além disso, as estruturas legisladoras formais estão sempre sujeitas a uma série de pressões e relações de forças que acabam por limitar o alcance das disposições legais que emanam desses espaços.

E ainda de acordo com Comte-Sponville (2005, p. 59), temos de considerar a ocorrência de situações nas quais
[...] a lei autoriza e que, no entanto, devemos nos vedar; outras que a lei não impõe, mas que devemos nos impor. A moral, do ponto de vista dos indivíduos, se soma à lei. É como um limite positivo: a consciência de um homem de bem é mais exigente que o legislador; o indivíduo tem mais deveres que o cidadão.

O mesmo vale do ponto de vista coletivo: um voto majoritário, numa democracia, que decrete que o racismo é legal (situação que é, no interior de uma república, perfeitamente possível), não mudaria a realidade imoral de tal legislação. Uma lei dessa natureza deve ser combatida e desobedecida, ainda que por uma minoria. Em situações específicas, a afirmação da moralidade pode exigir o rompimento com a lei. É assim também quando a desigualdade ou a injustiça predominam.

Os procedimentos repressores adotados pelos regimes totalitários que grassaram a América Latina e o Brasil, sempre que possível, buscaram se revestir de legalidade, embora fossem francamente imorais. Mesmo a legislação aplicada à área da saúde, de tempos em tempos, precisa ser revista para se adequar a problemas morais emergentes.

Nesse ponto temos um elemento chave na compreensão de um referencial que deveria nortear a atuação dos conselhos de saúde. É como um elemento de garantia da moralidade que a presença da sociedade civil deve se dar nos conselhos. Uma presença ostensiva, que deveria intimidar a ingerência dos técnicos e dos burocratas e coibir a exploração das brechas legais.

É nessa terceira ordem, a da moralidade, que o dito controle social passa a fazer sentido, tal como o termo é empregado na organização do Sistema Único de Saúde.

A estrutura dos conselhos, que exige a composição de $50 \%$ dos membros como representantes da sociedade civil, pode ser compreendida, portanto, como uma tentativa de garantir que, para além do que é cientificamente possível e daquilo que é legalmente viável, a gestão da saúde contemple o bem comum, compreendido aqui como a atenção às aspirações da comunidade. Teoricamente, a dinâmica das discussões no espaço dos Conselhos deveria tender a produzir um consenso que representasse, a um só tempo, a síntese mais acabada dessas três ordens. 
Contudo, existe uma distância importante entre a exposição teórica dos princípios que regem uma organização e a sua concretização ou manifestação empírica. As rupturas ideológicas, os interesses econômicos e uma série de outros obstáculos impedem uma adesão ingênua a essa ideia abstrata de bem comum. A sociedade civil é cindida por lutas e interesses antagônicos e eles estão presentes no cotidiano dos conselhos.

De toda forma, a participação popular é necessária na medida em que nem a ordem técnico-científica e nem a ordem jurídica são a garantia de que as necessidades efetivas serão contempladas.

\section{Conselhos de Saúde:}

\section{a institucionalização da participação social}

Com o SUS, a saúde emerge como questão de cidadania e a participação política como condição de seu exercício. 0 estabelecimento dos conselhos de saúde representou, indubitavelmente, uma inovação. Isso pelo fato de estabelecerem uma nova configuração da relação Estado/sociedade civil e trazerem consigo inúmeros avanços com a finalidade de garantir a participação social, a experiência de aprendizado cívico e de estabelecer as condições mínimas para que a negociação e a busca de um consenso democrático sobre os rumos da política sanitária no país fossem viáveis (Escorel, 2008).

No Brasil existem hoje mais de 5.500 conselhos, envolvendo cerca de 100 mil cidadãos e vasto número de associações, participando, debatendo e trabalhando em prol da saúde (Coelho, 2007).

Para a concretização das propostas de estabelecimento do pleno controle social surgiram inúmeros desafios, porém, muitas das dificuldades enfrentadas pelos conselhos decorrem da cultura construída ao longo da história política brasileira, marcada pelo predomínio da burocracia e pela ênfase em aspectos administrativos e técnicos (Gonçalves e col., 2008).

A legitimidade da argumentação técnico-científica, por exemplo, tende a impor o silêncio às experiências populares e a desautorizar o posicionamento de seus representantes (Delgado e Escorel, 2008).
Essa desigualdade, que marca a inserção e o desempenho dos diferentes atores na dinâmica dos conselhos, não se restringe apenas ao plano do saber formal. Ela também alcança, por exemplo, as condições materiais do exercício político do qual o conselheiro está incumbido. Diferentemente dos conselheiros do poder executivo, os representantes dos usuários não dispõem da infraestrutura relativa ao transporte, à disponibilidade de tempo e à assessoria institucional (Guizardi, 2006). Ou seja, a participação popular é condicionada por uma série de determinações econômicas, que acabam por dificultá-la e, em alguns casos, impedi-la.

O que se observa é a existência de um longo caminho para que os avanços da estrutura política possam ser capazes de assimilar as desigualdades sociais (Escorel, 2008). Isso é particularmente válido para um contexto como o brasileiro, onde as instituições democráticas são recentes, a participação popular é incipiente e os valores autoritários ainda predominam, dificultando as alterações nas relações econômicas e sociais.

Considerando os conselhos de saúde sob o aspecto de inovação institucional para a participação popular, apesar da fragilidade das bases do controle social e da gestão participativa, Van Stralen defende a possibilidade de renovação a qualquer momento, com o surgimento de novos padrões de interação e comunicação (Van Stralen e col., 2006).

Para Lattman-Weltman, os conselhos de saúde, como exemplo de aprimoramento e diversificação das formas institucionais, podem ser tomados como uma demonstração de resposta do sistema político “às demandas da sociedade por melhor governo, melhores serviços, mais direitos, mais universalidade/ universalização dos direitos" (Lattman-Weltman, 2008, p. 34), sendo que representam um importante instrumento para a construção da autonomia popular, para a capacitação da sociedade civil e para o desenvolvimento de cidadãos com maior experiência na defesa de seus interesses.

No próprio bojo do processo de desenvolvimento de uma cultura de participação democrática, a inclusão social passa a ser tomada como um processo dinâmico e que necessita ser conduzido e levado à prática, objetivando a conquista da verdadeira justiça social em saúde (Garrafa, 2005b). É nesse 
contexto que a ordem moral, cuja expressão teórica é o controle social, exerce um papel fundamental.

Os conselhos de saúde expressam, portanto, um grande desafio tanto para a sociedade civil como para o Estado, em diversas dimensões, tais como o reconhecimento dos diferentes interesses em disputa, a capacidade de negociação sem a perda da autonomia, a construção do interesse público e a participação na formulação de políticas públicas (Bravo e Souza, 2002).

\section{Conclusão}

As ideias de Comte-Sponville auxiliam na reflexão sobre a importância da participação da população no equilíbrio de forças entre o saber científico, a estrutura jurídica e os anseios efetivos da população. 0 controle social é a expressão da ordem moral que insere os debates sobre os rumos do SUS na arena da moralidade, colocando em perspectiva a orientação estritamente científica e o formalismo jurídico e submetendo-os a uma análise de cunho propriamente democrático.

A finalidade do embate entre esses diferentes pontos de vista é estabelecer o consenso cientificamente embasado, legalmente válido e, finalmente, socialmente desejado, sendo que a melhoria da qualidade de vida da população deveria ser considerada o valor moral norteador desse embate e o único resultado moralmente relevante, com o qual as demais ordens deveriam se comprometer e a partir do qual suas contribuições deveriam ser interpretadas.

Os estudos sobre os conselhos de saúde do SUS indicam a existência de uma significativa dificuldade na efetiva participação da população, apontando para a necessidade da construção de novos significados para esses espaços formais de participação social.

Nesse sentido, enfatiza-se que a participação política e o controle social não podem depender apenas de sua formulação legal, uma vez que eles somente se materializarão no conjunto das práticas sociais que constituem e atravessam o sistema de saúde (Guizardi, 2006).

Daí a necessária compreensão de que os conselhos de saúde não substituem os movimentos sociais e que são esses movimentos que devem nortear as ações dos conselhos.
A participação comunitária tem de ser mais ampla que os espaços formais de controle social, ampliando alianças com os movimentos populares, com as organizações não governamentais e com os órgãos públicos de controle. Assim, os conselhos de saúde poderão desempenhar seu papel e concretizar a base de sustentação de uma nova relação da população com o Estado, formando uma rede com força expressiva na luta por mudanças na sociedade brasileira.

\section{Referências}

ALVAREZ, M. C. Controle social: notas em torno de uma noção polêmica. São Paulo em perspectiva, São Paulo, v. 18, n. 1, p. 168-176, 2004.

BRASIL. Ministério da Saúde. Secretaria de Gestão Estratégica e Participativa. A construção do SUS: histórias da Reforma Sanitária e do processo participativo. Brasília: Ministério da Saúde, 2006.

BRAVO, M. I. S.; SOUZA, R. O. Conselhos de Saúde e Serviço Social: luta política e trabalho profissional. Ser social, Brasília, n. 10, p. 57-92, 2002.

COELHO, V. S. P. A democratização dos Conselhos de Saúde: o paradoxo de atrair não aliados. Novos estudos, São Paulo, n. 78, p. 77-92, 2007.

COMTE-SPONVILLE, A. O capitalismo é moral?. Tradução [de] Eduardo Brandão. São Paulo: Martins Fontes, 2005.

CORNWALL, A.; SHANKLAND, A. Engaging citizens: lessons from building Brazil's national health system. Social Science \& Medicine, Leicester, v. 66, n. 10, p. 2173-2184, 2008.

CRUZ, M. R.; TRINDADE, E. S. Bioética de Intervenção - uma proposta epistemológica e uma necessidade para sociedades com grupos sociais vulneráveis. Revista Brasileira de Bioética, Brasília, v. 2, n. 4, 2006.

DELGADO, M . M.; ESCOREL, S. Ensaio sobre a resolução 333/o3 do CNS: entre as dimensões política e técnica, e entre as dinâmicas participativa e fiscalizatória. Divulgação em saúde para debate, Rio de Janeiro, n. 43, p. 79-95, jun. 2008. 
ESCOREL, S. Conselhos de saúde: entre a inovação e a reprodução da cultura política. Divulgação em saúde para debate, Rio de Janeiro, n. 43, p. 23-28, jun. 2008.

GARRAFA, V. Introdução à Bioética. Revista do Hospital Universitário Ufma, São Luís, v. 6, n. 2, p. 9-13, 2005 a.

GARRAFA V. Inclusão social no contexto político da bioética. Revista Brasileira de Bioética, Brasília, v.1, n. 2, p.122-132, 2005b.

GARRAFA, V.; PORTO, D. Bioética, poder e injustiça: por uma ética de intervenção. $O$ mundo da saúde, São Paulo, v. 26, n. 1, p. 6-15, 2002.

GONÇALVES, A. O.; SILVA, J. F. S. ; PEDROSA, J. I. S. Contribuições da gestão participativa no espaço público chamado conselho: o contexto dos conselhos de saúde no Brasil. Divulgação em saúde para debate, Rio de Janeiro, n. 43, p. 96-105, jun. 2008.

GUIZARDI, F. L. Dilemas culturais, sociais e políticos da participação dos movimentos sociais nos Conselhos de Saúde. Ciência \& Saúde Coletiva, Rio de Janeiro, v. 11, n. 3, p. 797-805, 2006.
LATTMAN-WELTMAN, F. Democracia, representação, participação: a aposta do pluralismo institucional . Divulgação em saúde para debate, Rio de Janeiro, n. 43, p. 29-36, jun. 2008.

SÁNCHEZ VÁZQUEZ, A. Ética. Tradução [de] João Dell`Anna. 22. ed. Rio de Janeiro: Civilização Brasileira, 2002.

SILVA, J. O. Conselhos, controle social e racionalidade do Estado. Divulgação em saúde para debate, Rio de Janeiro, n. 43, p. 118-127, jun. 2008.

SPINK, M. J. P. Sobre a possibilidade de conciliação do ideal da integralidade nos cuidados à saúde e a cacofonia da demanda. Saúde e Sociedade, São Paulo, v. 16, n. 1, p. 18-27, 2007.

VAN STRALEN, C. J. et al. Conselhos de Saúde: efetividade do controle social em municípios de Goiás e Mato Grosso do Sul. Ciência \& Saúde Coletiva, Rio de Janeiro, v. 11, n. 3, p. 621-632, 2006. 